\title{
Negligencia y omisiones de la jerarquía católica sobre derechos sexuales $y$ reproductivos
}

\author{
Negligência e omissões da hierarquia católica sobre direitos \\ sexuais e reprodutivos
}
Negligence and omissions of the Catholic hierarchy on sexual and reproductive rights

Juan Guillermo Figueroa Perea*

\begin{abstract}
Resumen - En este texto se busca explorar el tema de la relación entre algunos elementos normativos de la tradición religiosa católica y las condiciones de posibilidad para ejercer derechos de sexualidad y reproducción, desde una referencia explícita a las categorías de negligencia y omisión, en parte porque los derechos humanos pueden violentarse por ambas razones, pero a la vez porque los rituales católicos incluyen en su discurso la omisión como un elemento importante de las faltas que debe reconocer toda persona. Valdría la pena reflexionar si existen omisiones entre personas católicas alrededor del espacio de la sexualidad y del de la reproducción que puedan asociarse a su lectura de la normatividad institucional, pero a la vez la negligencia suele atribuirse a autoridades de instituciones que no cumplen con una responsabilidad que les corresponde. En ese tenor, un paso adicional consiste en problematizar si la jerarquía de la institución puede llegar a omitir o incluso manipular el discurso normativo de la tradición a la cual representan, ya sea por prejuicios o ignorancia, o bien por una búsqueda intencional de mantener un sistema y orden social en temas de sexualidad y reproducción, quizás por aprendizajes de género de sus integrantes, o bien por otro tipo de motivaciones e intereses - conscientes o no - que valdría la pena analizar y documentar. Se detallan elementos subyacentes a dichos derechos para luego contrastarlos con los valores que se justifican desde la tradición católica, como la libertad de conciencia y, en la contraparte, la interpretación que hacen los jerarcas de la institución y los documentos oficiales de la misma, como el derecho canónico. Estas interpretaciones no coinciden y la hipótesis de este texto es que existe la posibilidad de que se está manipulando el sentido del discurso original y, por ende, incurriendo en omisiones y negligencia, con lo cual desestructurarlo podría contribuir a un ejercicio más integral de los derechos tanto de las personas creyentes como de quienes son influidos socialmente por el poder que tiene dicha institución en las normatividades de diferentes instituciones sociales.

Palabras clave: negligencia, omisión, sexualidad, reproducción, tradición católica.
\end{abstract}

\footnotetext{
* Profesor investigador en El Colegio de México. Correspondencia: Camino al Ajusco, 20 - Pedregal de Santa Teresa - Ciudad de México - MEXICO. CP: 10740. Email: <jfigue@colmex.mx>.
} 
Resumo - Este texto procura explorar a questão da relação entre alguns elementos normativos da tradição religiosa católica e as condições de possibilidade de exercer direitos de sexualidade e reprodução, a partir de uma referência explícita às categorias de negligência e omissão, em parte porque os direitos dos seres humanos podem ser violados por ambas as razões, mas, ao mesmo tempo, porque os rituais católicos incluem em sua omissão do discurso como um elemento importante das falhas que cada pessoa deve reconhecer. Vale a pena refletir sobre a existência de omissões entre os católicos em torno dos espaços da sexualidade e da reprodução que podem ser associados à leitura das normas institucionais, mas, ao mesmo tempo, a negligência é comumente atribuída às autoridades de instituições que não cumprem a responsabilidade que Ihes corresponde. Nesse sentido, um passo adicional consiste em problematizar se a hierarquia da instituição pode chegar a omitir ou mesmo manipular o discurso normativo da tradição a que representa, seja por meio de preconceito ou ignorância, seja através de uma busca intencional para manter um sistema e ordem social em questões de sexualidade e reprodução, talvez devido à aprendizagem de gênero de seus membros, ou outras motivações e interesses - conscientes ou não - que valerão a pena analisar e documentar. Detalham-se os elementos subjacentes a esses direitos que, em seguida, são contrastados com os valores justificados pela tradição católica, como a liberdade de consciência e, na contrapartida, a interpretação feita pelos hierarcas da instituição e seus documentos oficiais, como direito canônico. Essas interpretações não coincidem e a hipótese deste texto é que existe a possibilidade de que o sentido original do discurso esteja sendo manipulado e, portanto, incorrendo em omissões e negligências, com as quais desintegrá-lo poderia contribuir para um exercício mais abrangente dos direitos tanto dos fiéis como daqueles que são socialmente influenciados pelo poder que a instituição possui nos regulamentos das diferentes instituições sociais.

Palavras-chave: negligência, omissão, sexualidade, reprodução, tradição católica.

\begin{abstract}
This text seeks to explore the issue of the relationship between some normative elements of the Catholic religious tradition and the conditions of possibility to exercise sexuality and reproduction rights, from an explicit reference to the categories of negligence and omission, in part because human rights can be violated for both reasons, but at the same time because Catholic rituals in their discourse give prominence to omission as part of the faults that every person must recognize. It would be worth reflecting on whether there are omissions among Catholic people around the space of sexuality and reproduction that can be associated with their reading of institutional norms, but at the same time negligence is usually attributed to authorities of institutions that do not fulfill a responsibility which corresponds to them. In this sense, an additional step consists in problematizing whether the hierarchy of the institution can even omit or manipulate the normative discourse of the tradition which they represent, either through prejudice or ignorance, or through intentional search to maintain a system and social order in issues of sexuality and reproduction. This could happen perhaps due to gender learning of its members, or other motivations and interests - conscious or not - that would be worth analyzing and documenting. It details elements underlying these rights and then contrasts them with the values that are justified from the Catholic tradition, such as freedom of conscience and, on the counterpart, the interpretation made by the hierarchs and the official documents of the institution, as canon law. These interpretations do not coincide and the hypothesis of this article is that there is a possibility that the sense of the original discourse is being manipulated and therefore incurring in omissions and negligence. The elimination of these elements could contribute to a more comprehensive exercise of the rights of both believers
\end{abstract}




\section{ReVistg all pgutg}

\} NEGLIGENCIA Y OMISIONES DE LA JERARQUÍA CATÓLICA - PEREA, J. G. F. \}

DOI: $10.12957 /$ REP.2017.32750

and those who are socially influenced by the power this institution has in the regulations of different social institutions.

Keywords: neglect; omission; sexuality; reproduction; Catholic tradition.

\section{Introducción}

En este texto se busca sistematizar algunos de los componentes de los derechos en el ámbito de la sexualidad y la reproducción, para luego identificar si existe alguna relación posible con el planteamiento esperado de la jerarquía de una institución que se justifica a partir del discurso moral del fundador de la era cristiana. Esta reflexión explora el tema de la relación entre algunos elementos normativos de esta tradición religiosa y las condiciones de posibilidad para ejercer ambos tipos de derechos, pero desde una referencia explícita a las categorías de negligencia y omisión, en parte porque los derechos humanos pueden violentarse por ambas razones, pero a la vez porque los rituales católicos incluyen en su discurso la omisión como un elemento importante de las faltas que debe reconocer toda persona, antes de proceder a una ceremonia religiosa ${ }^{1}$.

Valdría la pena reflexionar si existen omisiones entre personas católicas alrededor del espacio de la sexualidad y del de la reproducción que puedan asociarse a (su lectura de) la normatividad institucional, pero a la vez la negligencia suele atribuirse a autoridades de instituciones que no cumplen con una responsabilidad que les corresponde. En ese tenor, un paso adicional consiste en problematizar si la jerarquía de la institución puede llegar a omitir o incluso manipular el discurso normativo de la tradición a la cual representan, ya sea por prejuicios o ignorancia, o bien por una búsqueda intencional de mantener un sistema y orden social en temas de sexualidad y reproducción, quizás por aprendizajes de género de sus integrantes, o bien por otro tipo de motivaciones e intereses (conscientes o no) que valdrían la pena analizar y documentar. Hablo de "negligencia pastoral" para aludir al daño de una "mala práctica" como intérprete de una tradición religiosa, a la par de una ciudadanía religiosa que defiende los derechos de las personas creyentes y de quienes son influidos por las intervenciones sociales justificadas por dicha tradición. Vale la pena profundizar en este horizonte analítico y político.

El uso de las categorías "negligencia" y "omisión" en el texto requieren ser contextuadas. La omisión es no hacer lo que se debería hacer o, bien, "puede definirse la omisión como aquel comportamiento pasivo con-

${ }^{1}$ El Confiteor o (por su traducción al español) "yo pecador" es una oración de confesión de pecados cometidos. 


\section{hevistg a}

\} NEGLIGENCIA Y OMISIONES DE LA JERARQUÍA CATÓLICA - PEREA, J. G. F. \}

DOI: $10.12957 /$ REP.2017.32750

sistente en la no ejecución de una acción determinada que, sobre la base de alguna norma, se esperaba que el sujeto realizara". (GIMBERNAT, 2003, p. 18).

Luis Ribó (1995) plantea que negligencia es la condición que debe cualificar los actos para que estos puedan estimarse culpables y por tanto, generadores de responsabilidad. En el Diccionario de Derecho (DE PINA; DE PINA VARA, 1997, p. 38), se establece que la "negligencia es el descuido o falta de atención en el cumplimiento de las obligaciones". Palomar de Miguel (2000, p. 1044) establece que "negligencia es el descuido o la imprudencia injustificada". Vale la pena preguntarse, si podría serle demandada a los jerarcas de la iglesia católica, omisión o negligencia en temas de derechos sexuales y reproductivos.

\section{El entorno de los derechos sexuales y los derechos reproductivos}

Es relevante explicitar qué incluyen los conceptos de sexualidad y de reproducción por una parte y cómo se modifican o se significan cada uno cuando se adjetivan desde la dimensión de los derechos. A la par también sería necesario reflexionar sobre lo que implica pensar ambas dimensiones de manera conjunta y problematizar a qué alude la separación de ambas experiencias en las construcciones de las identidades de las personas a partir de su diferenciación biológica, de sus edades, de sus estados conyugales, de sus orientaciones sexuales y de cualquier otra característica que pueda permear sus formas de vivir cada uno de estos entornos.

Con el fin de avanzar en ello, es interesante retomar las diferentes acepciones de la categoría de derechos, ya que, así como puede reconocerse la intención de servir como defensa y protección de individuos que pueden vivir situaciones de vulnerabilidad en momentos y contextos específicos, también se ha presentado como una reivindicación explícita ante situaciones de discriminación (LAFER, 1994; ÁVILA, 1999; CERVANTES, 2001; FIGUEROA, 2009, entre otros). Esto no contradice a la primera acepción, pero pareciera darle un papel diferente al titular del derecho: entre el ser protegido por otros o por algunas instituciones sociales, para pasar a visibilizar su capacidad de "agencia", después de haber sido minimizado, ignorado o no reconocido.

Otra variante analítica es pensar los derechos como recurso de los individuos titulares de los mismos para elegir opciones en ámbitos específicos donde se reconocen dichos derechos, si bien esta acepción puede suponer que dichas opciones pre-existen al proceso de decisión del sujeto, por lo que dicha persona tendría que escoger entre escenarios construidos por alguien más. En la contraparte, pueden interpretarse los derechos como un reconocimiento explícito a la capacidad moral de los sujetos para 


\section{ReVistg all paltg}

\} NEGLIGENCIA Y OMISIONES DE LA JERARQUÍA CATÓLICA - PEREA, J. G. F. \}

DOI: $10.12957 /$ REP.2017.32750

construir nuevas opciones, si acaso las existentes no le satisfacen en los espacios en los que se reconocen derechos. Esto les da un papel más activo, pues les reconoce la capacidad de cuestionar las normas existentes e incluso la posibilidad de adoptar alguna, pero igual sin cerrarles la posibilidad de resistirse a las mismas o bien a tratar de transformarlas. La clave sería reconocer que los derechos no son recetas uniformes que orienten el comportamiento de los sujetos titulares de los mismos, sino al contrario, un reconocimiento constante a la capacidad de los individuos de ir moldeando su propia historia, sin ignorar que el ejercicio de sus derechos tiene consecuencias en otros actores sociales también titulares de dichos derechos.

Por ende, vale la pena hacer referencia a otra acepción de los derechos, centrada en prerrogativas de individuos, pero con la característica de ser "individuos sociales" y no desde una "posición individualista", como si fueran sujetos aislados, que usan sus derechos como privilegios dependiendo de la posición social en la que se ubican. Es decir, se trata de garantías que tienen límites que van definiendo la convivencia cotidiana, pero que por ello pueden acarrear las jerarquías derivadas de la desigualdad social o bien la equidad producto de los avances democráticos de los ordenamientos logrados en grupos sociales y en poblaciones específicas.

Esto nos lleva a dos acepciones últimas, dentro de las que quisiera destacar, sin pretender que sea un recuento exhaustivo de los significados potencialmente atribuibles a los derechos. Estas aluden al derecho como una figura jurídica que le genera obligaciones a instituciones sociales respecto al entorno que viven los individuos de un espacio social, temporal e histórico determinado. Es decir, no basta con reconocerlos, sino que se asumen obligaciones y responsabilidades para monitorear las condiciones en los que pueden ejercerse. Ello nos lleva a una última interpretación, no excluyente de las anteriores, pero que sí enfatiza otros componentes y esta se refiere a pensar los derechos como un consenso de compromisos sociales que busca asegurar que las personas reconocidas como ciudadanos y ciudadanas logran acceder a las condiciones que les permiten poner en práctica dichos derechos.

Algo que ayudaría para un ejercicio analítico en dicha vertiente es identificar las formas en que los derechos pueden ser violentados o bien, no respetados, ya que tratando de contrarrestar dichas experiencias podría avanzarse en la inclusión cada vez mayor de los titulares de los mismos. De acuerdo a la literatura sobre el tema, se puede atentar contra los derechos por abuso, por negligencia, por discriminación o por omisión. De ser así valdría la pena intentar un ejercicio para evidenciar sujetos potencialmente vulnerables en sus derechos, así como actores e instancias sociales que llegan a participar en dichas exclusiones, omisiones o discriminaciones. Con ello puede identificarse el papel de una tradición religiosa, como la católica, en la prevención o bien en 1a legitimación de dichos abusos (PUELLO, 1998; CERVERA, 2005). 


\section{Las condiciones de posibilidad para los derechos desde una tradición religiosa}

En el caso de los derechos reproductivos, estos abarcan algunos derechos reconocidos nacional e internacionalmente, como lo son el derecho a decidir el número y espaciamiento de hijos, el derecho a disponer de la información, la educación y los medios para ello y el derecho a adoptar decisiones sobre la reproducción sin sufrir discriminación, coerción ni violencia. Para ello se requieren asegurar ciertas condiciones de posibilidad que faciliten la autodeterminación reproductiva, para lo cual es necesario cuestionar exclusiones de género o bien de cualquier otra índole. Autores como Sánchez Vázquez (1982) proponen que los actos humanos son más libres en la medida en que los sujetos que los llevan a cabo tienen menos coacciones para realizarlos. Dichas coacciones tienen que ver con presiones externas y con demandas internas, asumidas desde los procesos de socialización, los estereotipos de género, los valores morales y desde la misma personalidad del sujeto. Para ello es necesario que las personas se asuman con cierta autoridad moral para hacerlo y que no vivan las consecuencias negativas de sus decisiones como factores que las obligan a decidir en una sola vertiente.

El término "derechos sexuales" alude al derecho de toda persona a ejercer libremente su sexualidad. Al igual que en el caso de los derechos reproductivos, al referirlos a la sexualidad se demanda el derecho a decidir respecto a la propia sexualidad, sin que la persona se vea expuesta a coerción, discriminación o violencia. Habría que asegurar las condiciones de posibilidad para ello a través de la información y de los medios para tomar las propias decisiones, pero en este caso, aún más que en el de la reproducción, pareciera necesario delimitar lo que significa el reconocimiento de la diversidad en la sexualidad, así como el respeto a la libertad desde la "otredad". Es decir, ¿cómo pasar de la percepción de los otros como los extraños (o extranjeros) hacia el sí mismo como otro (RICOEUR, 2006) o bien a la construcción del "yotro" (FERNÁNDEZ 2007), a saber, el yo como el otro? La pregunta central es cómo relativizar nuestra lectura y práctica de la realidad sin asumir que es la única y, más aún, sin pretender que es la correcta. De no abordar esta reflexión, puede seguirse reproduciendo que las posiciones de quienes detentan el poder en una sociedad son las que tienen más posibilidades de constituirse y de legitimarse como las adecuadas. Ahora bien, podría argumentarse que desde cierta cosmovisión solamente hay una lectura de la realidad, como se ha argumentado en algunos momentos desde la jerarquía católica, pero a la vez se reconoce en la misma que un valor central subyacente a las prácticas morales es el de la libertad de conciencia (PAGLIERO, 2000; FIGUEROA, 2008). Hace falta, por ende, abundar sobre el significado de dicho valor, cuando pensamos en el dominio de la moral más que de la fe, en especial para identificar si una interpretación 


\section{ReVistg QIII PaVtg}

\} NEGLIGENCIA Y OMISIONES DE LA JERARQUÍA CATÓLICA - PEREA, J. G. F. \}

DOI: $10.12957 /$ REP.2017.32750

equívoca, ya sea generada intencional o accidentalmente, podría poner en riesgo los derechos de las personas que la asumen o la viven.

Otro componente relevante en la reflexión sobre los derechos alude a su connotación como derechos negativos y a su contraparte, como derechos positivos (CERVANTES; CITERONI, 2008). Los primeros son la base mínima, según la cual es necesaria la tolerancia como recurso de no agresión, ni discriminación, mientras que los segundos son una aspiración máxima, que pretende el respeto desde el como reconocimiento del valor de la "otredad"; es decir, de la posibilidad de nombrarse-visibilizarse en la diferencia, sin que ello signifique una deficiencia o un retroceso moral.

En el caso de la sexualidad, se han evidenciado falta de acceso a ejercicio integral de la misma a partir de las especializaciones de género, de las orientaciones sexuales, por cuestiones generacionales (por ejemplo grupos de edad "extremos", durante la niñez y adolescencia, así como en la vejez), por estado conyugal (en especial personas solteras o bien separadas de algún tipo de unión) e incluso por las representaciones que se han construido alrededor de las Ilamadas minusvalías, pero también asumiendo acríticamente "formas normales" de practicar la sexualidad.

En el ámbito de la reproducción, nuevamente son las mujeres como individuos y por grupos quienes más han sido identificadas como marginadas de los medios sociales y de la legitimidad para auto-determinarse en sus historias reproductivas, a la par que ha sido reconocida poco a poco la vulnerabilidad a la que están expuestas en estos espacios las personas no heterosexuales. A ello se añaden personas no fértiles, las que son solteras y quienes se han divorciado o que viven en uniones no formalizadas ante alguna institución. Es más reciente la referencia a los hombres como potenciales excluidos de decisiones en este tema, a partir de la "feminización de la reproducción" (FIGUEROA, 1998).

\section{Diferentes valoraciones morales dentro de una misma tradición religiosa}

En esta reflexión un paso siguiente a considerar consiste en problematizar qué le añade o le quita el construir normas sociales que influyen sobre los derechos en el ámbito de la sexualidad y de la reproducción, privilegiando ciertas lecturas religiosas de dichos procesos o incluso interpretaciones desde algunas tradiciones culturales o hasta disciplinarias que en algún momento pudieran estar legitimando o reproduciendo las discriminaciones o exclusiones anteriormente señaladas. Un paso más complejo consistiría en revisar si dichas lecturas o interpretaciones se imaginan como rígidas y únicas en el tiempo o bien si se recupera explícitamente sus cambios, ya sea por rectificación de errores o de enriquecimiento del saber asociado o bien porque se reconozcan actores y demandas sociales a ser consideradas en las normatividades de referencia. 


\section{hevistg a}

\} NEGLIGENCIA Y OMISIONES DE LA JERARQUÍA CATÓLICA - PEREA, J. G. F. \}

DOI: $10.12957 /$ REP.2017.32750

Si suponemos un primer escenario sin cambios en el tiempo, pero además con normas de tipo directivo, podría encontrarse que se legitiman interpretaciones que discriminan en ámbitos de la sexualidad y la reproducción, que limitan libertades y capacidad de decisión, que legitiman privilegios y jerarquías sociales y en el fondo, que desigualan a los seres humanos en sus derechos básicos. Es decir, si la tradición disciplinaria, cultural o religiosa (sin ser excluyentes) asume una lectura determinada y además es la visión dominante (independientemente de cómo se haya establecido), deja fuera a quien no se identifique con la misma. Adicionalmente, el escenario puede ser más complejo si se asume que solamente hay una respuesta o bien una interpretación posible al definir una norma.

Otro elemento analítico a considerar es cuando se asume que las disciplinas o las tradiciones de referencia están dirigiendo conductas, a diferencia de cuando se reconoce que están orientando o sugiriendo elementos a considerar en las decisiones que finalmente toman las personas. Sánchez Vázquez (1982) y Lamas (1996) aluden a visiones deontológicas, las cuales además consideran de manera definitiva la diferencia entre lo que puede hacerse y lo que debe prohibirse, mientras que describen como tautológicas las posturas interpretativas de las normas que demandan matizar y conocer el contexto y las intenciones en los que se desarrollan los comportamientos humanos, incluso antes de contrastarlos con alguna normatividad. La primera opción nuevamente puede dejar de lado a más personas que la segunda; si bien la segunda suele ser descalificada por relativista, habría que problematizar si la primera no podría caer en un tipo de totalitarismo que minimiza la capacidad de decisión y construcción de la realidad de los seres humanos.

Ahora bien, si se asume un segundo escenario en constante revisión tanto de las normas como de la interpretación de las mismas, lo que está asociado a ello es que no se suponen respuestas únicas a temáticas específicas, lo que supone un acercamiento más auto-crítico; ello implica una búsqueda constante de conocimientos sistemáticos y matizados. Esto se puede acompañar de un mayor pluralismo cultural, lo que obliga a "saberse escuchar" dentro de la diferencia, pero a la par a matizar la propia interpretación de la realidad, en especial en temas donde emergen constantemente lecturas maniqueas o permeadas por pre-juicios a veces no tan explícitos. Es decir, no se está pensando en este término como un adjetivo que (des)califica sino aludiendo a los supuestos de nuestros juicios.

Cualquiera que sea la respuesta a la reflexión anterior, lo que implica este segundo escenario es una mayor transparencia de acuerdos políticos al definir normas que pretendan acompañar la organización social, en especial si van a repercutir en personas con diferentes cosmovisiones, tradiciones religiosas y orígenes culturales. Ello supone asumir colectivamente una corresponsabilidad en el ejercicio de los diferentes derechos reconocidos a todo ser humano y de paso asegurar la igualdad jurídica de los diferentes ciudadanos, con el fin de poder ejercer garantías como la 


\section{ReVistg QIII paUtg}

\} NEGLIGENCIA Y OMISIONES DE LA JERARQUÍA CATÓLICA - PEREA, J. G. F. \}

DOI: $10.12957 /$ REP.2017.32750

libertad de conciencia, de pensamiento, de creencias y de culto, así como la libertad de expresión y de asociación.

La práctica jurídica y el trabajo con derechos humanos ha reconocido como relevantes las categorías de negligencia y omisión, para aludir a las responsabilidades no cumplidas por agentes institucionales alrededor de las condiciones para que los derechos puedan ser ejercidos, pero también podríamos diversificar la noción de omisiones para hacer referencia a las responsabilidades de la "agencia como ciudadanos", en términos de pedir cuentas a sus representantes y de apoderarse de sus derechos. En sintonía con este nivel de reflexión, proponemos reflexionar sobre "ciudadanía religiosa", como metáfora del uso político del término ciudadanía, sin pretender que las autoridades civiles vigilen el hacer de los intérpretes de una tradición religiosa, pero que no se ignoren las consecuencias de su discurso en los creyentes del mismo y en otras personas que conviven con normas permeadas por dichas referencias normativas. Para ello hemos sugerido también el concepto de "negligencia pastoral", aludiendo al ejercicio indebido de la autoridad para ser intérprete de una tradición religiosa en especial en temas de sexualidad y reproducción, si bien puede diversificarse su alcance.

\section{Algunos elementos recientes sobre la posición de la iglesia católica}

En este ejercicio reflexivo, vale la pena dar un paso más e incursionar en el análisis de algunas posiciones de la jerarquía católica alrededor de temas vinculados con derechos sexuales y reproductivos. Eso implica reconocer, para empezar, que se habla de la jerarquía y no explícitamente de la iglesia en general, pero además que la primera tampoco es homogénea, si para ello se consideran las afirmaciones o posicionamientos de personajes que son parte de la misma, así como algunos documentos y referencias normativas que usan como justificación de sus planteamientos.

Por ejemplo, una de las cartas pastorales que le dieron inicio al período del Ratzinger (Benedicto XVI) aludía a la necesidad de ser más cuidadosos con los criterios de selección de candidatos al sacerdocio, con el fin de evitar la incorporación de personas homosexuales, a menos de que éstas demostraran que estaban "curadas de dicha enfermedad", lo que muestra una concepción y representación muy específica de dicha orientación sexual. A pesar de ello, el obispo John Shelby Spong ha manifestado públicamente estar "cansado de sentir vergüenza por parte de (una) [mi] iglesia" que odia a los homosexuales. Incluso declara que eso es parte de una tiranía psicológica y de una ineptitud vergonzosa, pues contradice el sentido de la religión al legitimar el odio, el cual reconoce como incompatible con el origen de la tradición que representan.

Vale la pena referirnos a un discurso pronunciado por el presidente del gobierno español en abril de 2005, con motivo de la modificación del 


\section{hevistg a}

\} NEGLIGENCIA Y OMISIONES DE LA JERARQUÍA CATÓLICA - PEREA, J. G. F. \}

DOI: $10.12957 /$ REP.2017.32750

Código Civil Español con el fin de reconocer el derecho a contraer matrimonio a personas del mismo sexo. José Luis Rodríguez Zapatero señalaba "estamos construyendo un país más decente, porque no humilla a sus miembros". Es decir, enfatiza la reparación de discriminaciones ancestrales y añade posteriormente que "una sociedad que ahorra sufrimiento inútil a sus miembros es una sociedad mejor", ya que "hace retroceder el espacio de la humillación y la infelicidad". Valdría la pena preguntarse cuál de ambos planteamientos es más incluyente, pero además cuál parece más afín a los valores subyacentes a la tradición católica.

John Shelby destaca que "la justicia aplazada es una justicia negada" y por ende señala que "la igualdad de la ciudadanía no es algo que deba ser sometido nunca a un referéndum". Por ello no se limita a abogar por una iglesia donde "las personas homosexuales sean aceptadas como seres humanos iguales y completos, que tienen derecho legítimo a todos los derechos que tanto iglesia como sociedad ofrecen a cualquiera", sino que la "iglesia no sólo debería pedir disculpas, sino hacer penitencia pública por la forma en que (ha) [hemos] tratado a... las mujeres, a los adeptos a otras religiones..., así como a los gays y a las lesbianas".

¿Qué significa pedir disculpas, como sugiere el obispo Shelby y como de hecho lo hizo Juan Pablo II, al aludir por ejemplo a la segunda guerra mundial y al holocausto que tuvo lugar durante la misma? De acuerdo a la propia tradición católica y a los mandatos de sus procedimientos internos, una petición de disculpa supone un propósito de enmendar la falta cometida, en particular desde la lógica de no volver a repetirla. Sería interesante ligar esta reflexión a la noción de omisión incluida tanto en los discursos de derechos humanos como en uno de las principales oraciones de las ceremonias religiosas católicas. Es decir, pareciera que no evitar discriminaciones o bien ser indiferente ante las mismas (legitimándolas de alguna forma), podría ser motivo de abuso o violación a derechos humanos de personas concretas, en el caso de ser autoridad de instancias responsables de ello, pero a la vez, podría ser calificado como una falta (denominada "pecado") desde la lógica católica que alude a la necesidad de solidarizarse con las personas discriminadas o marginadas. Ahora bien, ¿qué sucedería cuando la lógica normativa avalada por los intérpretes oficiales de la institución le transmite a sus seguidores que esto es válido? ¿Cometerían alguna violación tanto a los derechos humanos como a los principios de la propia tradición quienes así lo interpretan? ¿Sería mayor o un agravante su posición al ser personajes que tienen influencia sobre el actuar de otros que confían en que ellos saben transmitir la forma de leer las normas de la institución a la que pertenecen?

Es muy frecuente que cuando se investiga y documenta (con diferentes criterios) lo que se considera la postura de la iglesia católica en temas específicos, se suele recurrir al discurso de la jerarquía, a pesar de que quienes son nombrados como laicos (no por la categoría de laicidad sino por no 


\section{ReVistg all paltg}

\} NEGLIGENCIA Y OMISIONES DE LA JERARQUÍA CATÓLICA - PEREA, J. G. F. \}

DOI: $10.12957 /$ REP.2017.32750

ser jerarcas) también son parte de la institución y, de hecho, son el componente mayoritario (CONCILIO VATICANO II, 1968, 1972). ¿Cómo recuperar sus posicionamientos en estos temas?

\section{Ejercicios de disidencia en el entorno de la iglesia católica}

Es interesante contrastar la posición del grupo de Católicas por el Derecho a Decidir con el de un grupo de católicas colombianas (también feministas como las primeras), respecto a lo que procede hacer cuando las personas creyentes no se identifican con quienes coordinan burocrática y pastoralmente a la institución. Las primeras han propuesto de diferentes formas una revisión de la interpretación que se hace de la jerarquía en la búsqueda de asegurar el ser incluyente y solidario en las diversas prácticas sociales al interior y fuera de la propia pertenencia religiosa (CATOLICAS POR EL DERECHO A DECIDIR 1998a y 1998b), algo que no identifican en diferente posiciones de la jerarquía, mientras que las segundas han optado por renunciar a la iglesia, dados sus componentes fundamentalistas, anacrónicos, misóginos, homofóbicos, machistas, patriarcales y antifeministas.

No es un tema menor comentar la propuesta que presentó el segundo grupo, el cual optó por promover como protesta la salida voluntaria y masiva de la iglesia de todas aquellas personas que ya no se identifican ni como fieles ni como creyentes, pero argumentando características de la institución que otras personas podrían afirmar que no son una parte consustancial de la misma (PLANETA PAZ). Es decir, si lo homofóbico, misógino, patriarcal y antifeminista, por repetir solamente algunas de las categorías mencionadas previamente, así como el afirmar que se distancian de la misma "por imponer, en alianza con políticos, gobernantes y sectores conservadores, la maternidad obligatoria y no deseada a las mujeres", pudiera ser cuestionado como "lo propio de esta tradición religiosa", sería factible monitorear y demandar qué tanto se manipula el discurso institucional.

Adicionalmente, vale la pena no olvidar que quienes lo hacen (de ser el caso) están violentando derechos, ejerciendo un abuso del poder y desvirtuando una cosmovisión, que a la par ha generado múltiples acciones de solidaridad en momentos críticos para diferentes poblaciones, como lo son las épocas de hambrunas, la discriminación a quienes viven con alguna discapacidad o bien quienes padecen alguna enfermedad, por mencionar solamente algunas. Se podrían incluso identificar jerarcas que se han solidarizado con personas y poblaciones a quienes les han violentado sus derechos humanos, por lo que más que generalizar una sola posición, habría que profundizar en las normatividades que parecen tener mayor preponderancia normativa y analizar si hay interpretaciones en disputa y que requieren negociarse o bien, si puede hablarse de una intención deliberada de imponer alguna lectura (aunque sea incompleta y reduccionista), por 
ejemplo por el interés de mantenerse en el poder (al no reconocerle los mismos derechos a las mujeres) o bien por lo que el obispo Shelby describe como "ineptitud vergonzosa" y hasta por alianza con grupos de poder (como describe Ortiz Ortega " 2000, "los pactos entre caballeros" de la jerarquía católica con los líderes políticos, para legislar sobre el aborto). De ser este el caso ¿qué papel jugarían las personas creyentes laicas y su potencial proceso de ciudadanía, incluso dentro de la institución?

Antes de dar un paso más en esta reflexión, vale la pena retomar algunos elementos de lo que incluyen dentro del Derecho de Petición las compañeras que promovieron una renuncia libre y voluntaria a ser parte de la iglesia ${ }^{2}$. En un formato dirigido al Arzobispo de Medellín el 25 de noviembre de 2009 (fecha en la que se conmemora el día internacional en contra de la violencia hacia las mujeres), afirman que "la iglesia católica es una institución antidemocrática, autoritaria y violenta, que niega el libre desarrollo de la personalidad, la libertad de cultos, la libertad de cátedra y la objeción por conciencia, al imponer en la sociedad una única conciencia de carácter religioso." ${ }^{3}$ Por lo tanto, manifiestan que "haciendo uso de (su) [mi] inalienable derecho a la libertad de conciencia y a (su) [mi] capacidad de razonamiento crítico, sobre el significado de (su) [mi] adscripción a la fe católica, y por consiguiente a la Iglesia Católica...desean expresar en absoluta libertad, (su) [mi] contradicción con la adscripción a una entidad caracterizada por su dogmatismo" y a la par que "la fidelidad a la propia conciencia es un derecho constitucional reconocido por la legislación en el art. 18 de la constitución" (de Colombia). Por lo mismo, solicitan su "exclusión a todos los efectos - incluso los estadísticos -, del registro de personas bautizadas a la fe católica y el reconocimiento del acto de apostasía que, por esta declaración expreso, haciendo uso de los legítimos derechos a disponer libremente de mis convicciones morales, éticas y religiosas". Valdría la pena documentar las opiniones de diferentes personas ante este recurso de apostasía ${ }^{4}$, en especial cuando cada vez más personas de diferentes poblaciones se auto-describen como "católicos no practicantes". Es decir, como alguien que reconoce una pertenencia, pero que a la par toma distancia de la misma, quizás por discrepancias en algunos contenidos normativos.

Lo que sí es posible afirmar es que una lectura de intolerancia a la diferencia por la falta de costumbre de convivir con la misma. Sánchez Vázquez (1982) y Lamas (1996), entre otros autores, caracterizan dos formas

\footnotetext{
2 Derecho de petición al Arzobispo de Medellín, Renuncia a la iglesia católica, 2009. Disponible en: <http:// redesciudadanasjalisco.blogspot.mx/2009/11/25-de-noviembre-dia-por-la-eliminacion.html>. Acceso en: ago. 2017.

${ }^{3}$ Carta Abierta: La realidad sobre la protesta del 26 de noviembre en contra de la iglesia católica, en defensa del Estado laico y del derecho a las mujeres a decidir, Planeta Paz. Sectores Sociales Regulares para la Paz en Colombia. Disponible en: <http://planetapaz.org/component/content/article?id=195:la-realidad-sobre-la-protestacontra-la-iglesia-catolica\&catid=59:noticias-del-conflicto>. Acceso en: ago.2017.

${ }^{4}$ Renunciar a la fe católica, a la Iglesia y a todos sus preceptos. Es el anulamiento del sacramento del bautismo, por el que se declara a una persona católica, y el rompimiento de todo lazo con la Iglesia católica. Es un derecho que tiene cualquier católico en base a la libertad de culto y, como tal, se puede ejercer con total libertad.
} 


\section{ReVistg all pgutg}

\} NEGLIGENCIA Y OMISIONES DE LA JERARQUÍA CATÓLICA - PEREA, J. G. F. \}

DOI: $10.12957 /$ REP.2017.32750

de construir juicios morales: una deontológica y otra que denominan teleológica. Según la primera, los comportamientos son buenos o malos por definición, mientras que en la segunda se reconocen matices, de acuerdo al contexto de las intenciones, por lo que no existen calificaciones únicas de los actos humanos. La segunda lectura puede ser más incluyente que la primera, ya que una lectura más definitiva puede ser a la vez menos tolerante ante la diversidad de condiciones sociales, culturales e históricas. El problema es cuando la diferencia genera temor y rechazo, detonando en muchos casos violencia y discriminación.

Un ejemplo de ello es la homofobia internalizada, a la que alude Mariana Castañeda (1999) y ello tiene múltiples ejemplos en la jerarquía católica, pero a la vez en seguidores acríticos de sus discursos e interpretaciones. ¿Tendrá alguna responsabilidad el discurso aprendido a partir de lo dicho por la jerarquía? Algo análogo sucede en el campo de los derechos reproductivos, por ejemplo, alrededor de la autodeterminación reproductiva de las mujeres, sin querer sugerir que con ello se agota dicho concepto. Es más que conocido el rechazo a la posibilidad de ciertas formas de regulación de la fecundidad, pero más aún de la interrupción de un embarazo, incluso en situaciones donde la vida de la mujer embarazada se encuentre en riesgo o en que dicho embarazo sea el producto de una violación. Es poca la difusión que se le ha dado a voces que se consideran disidentes dentro de la propia teología católica, según las cuales no puede sancionarse moralmente a una persona cuando actúa de acuerdo a su conciencia y más aún cuando la normatividad católica no reconoce dogmas morales sino solamente dogmas de fe. Dentro de dicha tradición tiene un valor central la libertad de conciencia e incluso hasta 'la obligación moral' de actuar de acuerdo a la misma (PAGLIERO, 2000; MÚNERA, 2003). Esto es más que la pura obediencia a los comentarios u opiniones de líderes, quienes en muchos contextos no matizan la norma y, al contrario, presentan como certeza respuestas que son una de las varias interpretaciones posibles.

Otra vertiente de preguntas y de diálogo a considerar es cómo se toma en cuenta en la normatividad el conjunto de prácticas de la población creyente (suponiendo que a la jerarquía le interesa el caso), e incluso de aquella que no se identifica con la tradición religiosa pero que es influida por sus discursos y normas, que vive las experiencias reproductivas (y las sexuales) en una vertiente distinta a la de la interpretación dominante de la jerarquía. Para especificar esta pregunta retomo dos experiencias en diferentes regiones del mundo, pero a la vez valdría la pena no olvidar el acuerdo del Concilio Vaticano II en términos de reconocerle una mayor autoridad a la población de seglares; es decir, creyentes que no ocupan alguna posición jerárquica en la lógica institucional.

Una experiencia a considerar es la documentada sobre el tema del aborto y la anticoncepción en Uruguay, Paraguay y Argentina a mediados de la década de los noventa. En este caso, mujeres católicas reconocían 


\section{hevistg a}

\} NEGLIGENCIA Y OMISIONES DE LA JERARQUÍA CATÓLICA - PEREA, J. G. F. \}

DOI: $10.12957 /$ REP.2017.32750

que se sentían abandonadas por la jerarquía lo que les generaba vivir conflictos morales de manera solitaria y con culpas, si bien reconocían que el ser superior a quien los sacerdotes decían representar seguramente era más comprensivo que sus intermediarios, aunque no los confrontaban a estos por el temor a ser excluidas de la institución. A la par, algunas de ellas reconocían que el discurso feminista sobre el valor de la dignidad como mujeres les había posibilitado reconciliarse con la tradición religiosa a la que deseaban pertenecer, como lo es la católica (MAZZOTI; PUJOL; TERRA, 1994). Irónicamente, el feminismo ha sido cuestionado por la jerarquía de la institución, argumentando que atenta los valores de la familia y las funciones que dentro de la misma ocupan hombres y mujeres. Estas mujeres mostraban una disidencia práctica con respecto a las normas institucionales alrededor de dos espacios de sus experiencias reproductivas, pero a la par reconocían una rigidez en quienes detentan el poder dentro de la jerarquía, por lo que preferían hacerles sentir que los obedecían, a pesar de los conflictos que tenían que vivir de manera aislada. ¿Habrá algo que cuestionarle a la jerarquía o bien es objeto de descalificación el quehacer de las mujeres al argumentar que actuaron de acuerdo a lo que "su conciencia y necesidades les dictan" (MAZZOTI; PUJOL; TERRA, 1994)?

Una segunda experiencia es la documentada en diferentes países del mundo, con población católica a propósito de temas como la anticoncepción, el aborto y el divorcio. En un documento publicado a fines del segundo milenio, se constató que existe una importante distancia entre las referencias normativas de diferentes documentos de la iglesia y las prácticas cotidianas de personas que se describen como parte de la institución en cuestión. Lo que es interesante de considerar es que no pocas de dichas personas le dan una justificación católica a sus comportamientos distanciados de la lógica desde la que se interpretan jerárquicamente las normas; es decir, por el valor de su dignidad, por su mayor tranquilidad como "personas de bien" y por algunas consideraciones a actuar bien con su descendencia, afirman actuar de acuerdo a su conciencia, aunque eso signifique reinterpretar lo escuchado de los jerarcas o bien decidir que en ámbitos tan personales como la reproducción, ellas también son autoridades como para tomar sus propias decisiones. Irónicamente una de las conclusiones de este estudio, es que "la mayor parte de los católicos no obedecen las normas institucionales", si bien podríamos afirmar que sí "obedecen a su conciencia". ¿Acaso cometen, por eso, alguna irregularidad moral, en lo general y en lo católico?

Sócrates señalaba que él era más sabio en la medida en que no pretendía saber lo que no sabía ${ }^{5}$. Es decir, más que por erudición, su sabiduría

${ }^{5}$ El filósofo griego Platón hace referencia a esta reflexión en su diálogo Menón (un conocido dicho que se deriva de lo relatado por el filósofo griego Platón sobre Sócrates), también Ilamado Menón, o de la Virtud, es un diálogo de Platón que se vincula al Protágoras. Contiene una reflexión sobre la esencia de la naturaleza de la virtud (ñåôP) y habla sobre la posibilidad para enseñarla y los problemas relativos a cómo se puede obtener a través de la teoría del conocimiento. (PLATON, 1958). 


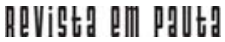

\} NEGLIGENCIA Y OMISIONES DE LA JERARQUÍA CATÓLICA - PEREA, J. G. F. \}

DOI: $10.12957 /$ REP.2017.32750

se centraba en reconocer los límites de su conocimiento. Esto obliga a matizar afirmaciones, a contextualizarlas y a reconocer que hay otros saberes por incorporar al propio, el cual además requiere revisarse constantemente.

\section{Recursos para revisar las condiciones de posibilidad para el ejercicio de los derechos}

Propongo reflexionar sobre el conjunto de criterios subyacentes a la interpretación oficial de la iglesia católica al hablar sobre sexualidad y reproducción. Se busca mostrar la existencia de lecturas en tensión dentro de la propia institución, a la vez que la forma en que la jerarquía impone las interpretaciones que sostiene y minimiza la posibilidad de negociar con la diferencia al interior de la institución, al margen de la legitimidad moral, teológica y discursiva de otros miembros de la misma. No se pretende repetir ni sistematizar lo dicho por la institución a propósito del ejercicio de la sexualidad y la reproducción, sino especular sobre el manejo de los discursos por parte de diferentes actores sociales y tratar de socializar una categoría que parece útil desde un punto de vista analítico y político, como lo es "la negligencia pastoral".

La negligencia pastoral alude al ejercicio indebido de la función que tienen las personas que dentro de la iglesia católica son reconocidas como intérpretes de la doctrina, por el hecho de ser quienes transmiten las normas de la institución. Cuando se habla de ejercicio indebido se hace referencia a no cumplir las mismas normas de la institución, como lo es la necesidad de actualizarse en el conocimiento acumulado sobre aquello que no es objeto de dogma sino de decisiones individuales de los creyentes de la tradición religiosa; esta desactualización u ocultamiento del conocimiento acumulado puede evitar que los individuos actúen de acuerdo a su conciencia, pues no hay certezas que apoyen una conducta única. Por abuso de autoridad dicho ejercicio del poder puede generar daños a los derechos humanos de personas creyentes y de las no creyentes.

Para el tema de los derechos humanos, importa explorar algunos ejercicios de lo que denomino ciudadanía religiosa, en la medida en que los sujetos creyentes se apropian activamente de las normas institucionales, a través de su introyección y resignificación, a partir del actuar de acuerdo a su conciencia, al margen de que ello a veces contradiga los discursos institucionales oficiales. La ciudadanía religiosa alude a la capacidad de reconocerse teniendo derechos dentro de una institución religiosa, sin necesidad de ser parte de la jerarquía burocrática de una institución. Se habla de ciudadanía religiosa para distinguirla del uso político del término, pero reconociendo algunas analogías y explorando algunas analogías y metáforas.

Vale la pena citar a Marty, Guin y Greenfield (1998), quienes sistematizan los principios que denominan "el discurso civil religioso", mientras que Morelo (2003) hace una revisión de los derechos de los católicos 


\section{hevigtg all pattg}

\} NEGLIGENCIA Y OMISIONES DE LA JERARQUÍA CATÓLICA - PEREA, J. G. F. \}

DOI: $10.12957 /$ REP.2017.32750

en la iglesia y cuestiona las razones por las que la jerarquía de la institución se resiste a difundir dichos derechos (PUELLO, 1998; CERVERA, 2005). Con estos referentes, puede decirse que se es ciudadano ante un Estado que reconoce los derechos y que busca asegurar las condiciones para su ejercicio; en la iglesia católica se tiene una estructura jerárquica que pareciera ignorar derechos de los "no jerarcas" pero a la vez cuenta con elementos normativos que les reconocen autoridad a todos sus miembros, al margen de ser parte de la jerarquía formal o de la burocracia de la institución.

Este texto busca construir algunas propuestas para el estudio de los "derechos de los creyentes", así como la acotación de las responsabilidades de las personas que son parte de la jerarquía institucional. Para ello, se proponen seguir explorando la dimensión del abuso del poder a través de la intimidación moral hacia los creyentes, pero a la par, reconociendo algunas coincidencias del discurso católico con los derechos humanos en el ámbito de la sexualidad y de la reproducción. ¿Podríamos avanzar un poco más explicitando omisiones, imprudencias injustificadas, daños provocados y concluyendo con procesos tanto de reparación de daños como de prevención de los mismos?

En este momento, valdría la pena retomar una cita de María Van Doren (2011), teóloga feminista, quien recuerda que el propio Benedicto $\mathrm{XVI}$, señalaba en 1968 (cuando era el teólogo Joseph Ratzinger), que "la conciencia personal está arriba del Papa, también contra los requisitos (las formalidades) de una autoridad eclesial". Es necesario problematizar la noción de obediencia a la autoridad (si esta se identifica como los jerarcas) a partir de revisar la importancia primordial que tiene la conciencia personal en la moral católica. Algunos teólogos plantean que sería inmoral no obedecer a la conciencia, incluso con el argumento de estar defendiendo a la autoridad institucional. Lo complejo es cuando las personas creyentes de dicha institución desconocen el valor (y la obligatoriedad) que tiene su propia conciencia como guía de sus comportamientos o más aún, que la obedecen, pero viviéndolo con culpas y experimentando conflictos innecesarios. ¿Lo podemos seguir dialogando? 


\section{ReVistg all pavtg}

\} NEGLIGENCIA Y OMISIONES DE LA JERARQUÍA CATÓLICA - PEREA, J. G. F. \}

DOI: $10.12957 /$ REP.2017.32750

\section{Referencias}

ÁVILA, M. B. Feminismo y ciudadanía: la producción de nuevos derechos. In: SCAVONEL (Coord.). Género y salud reproductiva en América Latina. Costa Rica: Cartago Libro Universitario Regional, 1999.

CASTAÑEDA, M. La experiencia homosexual. Para comprender la homosexualidad desde dentro y desde fuera. México: Paidós, Contextos, 1999. CATOLICAS POR EL DERECHO A DECIDIR. La opinión católica ante la reproducción. Un panorama mundial. Estudios de actitudes y prácticas. Católicas por el Derecho a Decidir, México, D.F. 1998a.

CATOLICAS POR EL DERECHO A DECIDIR. La primacía de la conciencia. Católicas por el Derecho a Decidir, México D.F. 1998b.

CERVANTES, A. Universalización, desigualdad y ética: intervenciones en la teorización sobre derechos humanos. In: FIGUEROA, J. G. (Coord.). Elementos para un análisis ético en la reproducción. México: Editorial Porrúa, Universidad Nacional Autónoma de México, 2001.

CERVANTES, A.; CITERONI, T. Los derechos sexuales y la desarticulación del heterosexismo: tolerancia, reconocimiento y liberación. In: SZASZI.; SALASG. (Coord.). Sexualidad, derechos humanos y ciudadanía. México: El Colegio de México, 2008.

CERVERA, R. Derechos humanos e iglesia católica. In: Los derechos humanos dentro de la iglesia católica. México: Católicas por el Derecho a Decidir, 2005.

CONCILIO VATICANO II. Comentario a la constitución Gaudium et Spes sobre La iglesia en el mundo de hoy. Madrid: Biblioteca de autores cristianos, 1968.

1972.

. Documentos completos del Vaticano II. México: Librería Parroquial,

DE PINA, R.; DE PINA, V. R. Diccionario de Derecho. México: Editorial Porrúa, 1997.

FERNÁNDEZ, G. C. Masculinidad: errática zaga de un lugar imposible. In: JIMÉNEZ, L.; TENA, O. (Coord.). Reflexiones sobre masculinidades y empleo. México: Universidad Nacional Autónoma de México, 2007.

FIGUEROA, J. G. Una aproximación a los derechos sexuales y derechos reproductivos desde la laicidad. Revista Sexología y Sociedad, La Habana, Cuba: Editorial Cenesex, año 15, n. 39, 2009.

- La libertad de conciencia en la tradición católica: una opción para el ejercicio de los derechos en el ámbito de la sexualidad. In: SZASZI; 


\section{hevistg a}

\} NEGLIGENCIA Y OMISIONES DE LA JERARQUÍA CATÓLICA - PEREA, J. G. F. \}

DOI: $10.12957 /$ REP.2017.32750

SALASG (Coord.). Sexualidad, derechos humanos y ciudadanía. Diálogos sobre un proyecto en construcción. México: El Colegio de México, 2008.

. Algunos elementos para interpretar la presencia de los varones en los procesos de salud reproductiva. Cadernos em Saúde Pública, Río de Janeiro, v. 14, suplemento 1, 1998.

GIMBERNAT, O. E. Estudios sobre el delito de omisión. México: Instituto Nacional de Ciencias Penales, 2003.

LAFER, C. La reconstrucción de los derechos humanos. Un diálogo con el pensamiento de Hannah Arendt. México: Fondo de Cultura Económica, 1994.

LAMAS, M. La bioética: proceso social y cambio de valores. In: CAREAGA, G.; FIGUEROA, J. G.; MEJÍA, M. C. (Coord.). Ética y salud reproductiva. México: Programa Universitario de Estudios de Género, 1996.

MARTY, M. E.; GUIND, E.; GREENFIELDL. To speak and be heard. Conscience, Washington, v. XIX, n. 4, 1998.

MAZZOTTI, M.; PUJOL, G.; TERRA, C. Una realidad silenciada. Sexualidad y maternidad en mujeres católicas. Uruguay: Católicas por el Derecho a Decidir, 1994.

MORELO, S. Catholics are the church. What catholics need to know, and why the hierarchy doesn't want us to. Conscience, Washington, v. XXI, n. 3, 2003.

MÚNERA, A. Fundamentalismo en la Iglesia Católica. Conciencia Latinoamericana, México, v. XIII, n. 6, 2003.

ORTIZ ORTEGA, A. Si los hombres se embarazaran, ¿el aborto sería legal? Las feministas ante la relación Estado-iglesia católica en México (1871-2000). México: Edamex y El Population Council, 2000.

PAGLIERO, M. La primacía de la conciencia y la libertad de decidir de las mujeres. Conciencia Latinoamericana, México, v. XII, n. 3, 2000.

PALOMAR DE MIGUEL, J. Diccionario para juristas. México: Editorial Porrúa, 2000.

PLANETA PAZ. Carta abierta: la realidad sobre la protesta del 26 de noviembre en contra de la iglesia católica, en defensa del Estado laico y del derecho a las mujeres a decidir. Planeta Paz "Sectores Sociales Regulares para la Paz en Colombia. Disponible en: <http://planetapaz.org/component/content/ article?id=195:Ia-realidad-sobre-la-protesta-contra-la-iglesia-catolica\&catid =59:noticias-del-conflicto>. Acceso en: ago. 2017.

PLATON. Menón. Estudio crítico, traducción y notas por Antonio Ruiz de Elvira. Madrid:Instituto de Estudios Políticos. 1958 (Reimpresión 1970). 


\section{ReVistg QIII PaUtg}

\} NEGLIGENCIA Y OMISIONES DE LA JERARQUÍA CATÓLICA - PEREA, J. G. F. \}

DOI: $10.12957 /$ REP.2017.32750

PUELLO, Y. Derechos Humanos en la Iglesia Católica desde la perspectiva de las mujeres. Conciencia Latinoamericana, São Paulo: CDD-Brasil, v. X, n. 2, jul./dic. 1998.

REDES CIUDADANAS JALISCO. Derecho de petición al Arzobispo de Medellín. Renuncia a la iglesia católica, 2009. Disponible en: <http:// redesciudadanasjalisco.blogspot.mx/2009/11/25-de-noviembre-dia-por-laeliminacion.html>. Acceso en: ago. 2017.

RIBÓ, L. Diccionario de derecho. Barcelona: Bosch, Casa Editorial, 1995.

RICOEUR, P. Sí mismo como otro. México: Siglo XXI, 2006.

SÁNCHEZ, V. A. Ética. México: Grijalbo, 1982.

SHELBY S., J. A Manifesto! The Time Has Come! 2009. Disponible en: <http:/ /walkingwithintegrity.blogspot.mx/2009/10/manifesto-from-our-friendbishop-john.html>. Acceso en: ago. 2017.

VAN DOREN, M. La conciencia personal está arriba del papa, también contra los requisitos (las formalidades) de una autoridad eclesial (J. Ratzinger, 1968). 2011. Disponible en: <https://mariavandoren.wordpress.com/2011/07/04/ $\%$ e2\%80\%9cla-conciencia-personal-esta-arriba-del-papa-tambien-contralos-requisitos-las-formalidades-de-una-autoridad-eclesial\%e $2 \% 80 \% 9 \mathrm{~d}$-jratzinger-1968/>. Acceso en: ago. 2017.

ZAPATERO, J. L. R. Discurso en el Congreso por la aprobación del matrimonio gay. Cadena ser, 2005. Disponible en: <http://cadenaser.com/ser/ 2005/07/01/espana/1120175411_850215.html>. Acceso en: ago. 2017.

DOI: $10.12957 /$ rep.2017.32750

Recebido em 21 de outubro de 2017.

Aprovado para publicação em 18 de novembro de 2017.

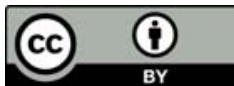

A Revista Em Pauta: Teoria Social e Realidade Contemporânea está licenciada com uma Licença Creative Commons Atribuição 4.0 Internacional. 